\title{
Brown fat activation reduces hypercholesterolaemia and protects from atherosclerosis development
}

Jimmy F.P. Berbée $e^{1,2, \star}$, Mariëtte R. Boon ${ }^{1,2, \star}$, P. Padmini S.J. Khedoe ${ }^{1,2,3, \star}$, Alexander Bartelt $4,5, \star, \S$, Christian Schlein ${ }^{4}$, Anna Worthmann ${ }^{4}$, Sander Kooijman ${ }^{1,2}$, Geerte Hoeke ${ }^{1,2}$, Isabel M. Mol ${ }^{1,2}$, Clara John $^{4}$, Caroline Jung ${ }^{6}$, Nadia Vazirpanah,1,2, Linda P.J. Brouwers ${ }^{1,2}$, Philip L.S.M. Gordts ${ }^{7}$, Jeffrey D. Esko7, Pieter S. Hiemstra ${ }^{3}$, Louis M. Havekes ${ }^{1,2,8,9}$, Ludger Scheja ${ }^{4}$, Joerg Heeren ${ }^{4, \S} \&$ Patrick C.N. Rensen ${ }^{1,2, \S}$

Brown adipose tissue (BAT) combusts high amounts of fatty acids, thereby lowering plasma triglyceride levels and reducing obesity. However, the precise role of BAT in plasma cholesterol metabolism and atherosclerosis development remains unclear. Here we show that BAT activation by $\beta 3$-adrenergic receptor stimulation protects from atherosclerosis in hyperlipidemic APOE`3-Leiden.CETP mice, a well-established model for human-like lipoprotein metabolism that unlike hyperlipidemic Apoe ${ }^{-/-}$and $L d l r^{-/-}$mice expresses functional apoE and LDLR. BAT activation increases energy expenditure and decreases plasma triglyceride and cholesterol levels. Mechanistically, we demonstrate that BAT activation enhances the selective uptake of fatty acids from triglyceride-rich lipoproteins into BAT, subsequently accelerating the hepatic clearance of the cholesterol-enriched remnants. These effects depend on a functional hepatic apoE-LDLR clearance pathway as BAT activation in Apoe / - $^{-}$ and $\mathrm{Ldll}^{-I^{-}}$mice does not attenuate hypercholesterolaemia and atherosclerosis. We conclude that activation of BAT is a powerful therapeutic avenue to ameliorate hyperlipidaemia and protect from atherosclerosis.

\footnotetext{
${ }^{1}$ Division of Endocrinology, Department of Medicine, Leiden University Medical Center, Albinusdreef 2, Leiden 2333 ZA, The Netherlands. ${ }^{2}$ Einthoven Laboratory for Experimental Vascular Medicine, Leiden University Medical Center, Albinusdreef 2, Leiden 2333 ZA, The Netherlands. ${ }^{3}$ Department of Pulmonology, Leiden University Medical Center, Albinusdreef 2, Leiden 2333 ZA, The Netherlands. ${ }^{4}$ Department of Biochemistry and Molecular Cell Biology, University Medical Center Hamburg-Eppendorf, Martinistraße 52, Hamburg 20246, Germany. ${ }^{5}$ Department of Genetics and Complex Diseases, Harvard School of Public Health, Boston, Massachusetts 02115, USA. ${ }^{6}$ Diagnostic and Interventional Radiology, University Medical Center Hamburg-Eppendorf, Martinistraße 52, Hamburg 20246, Germany. ${ }^{7}$ Department of Cellular and Molecular Medicine, University of California-San Diego, La Jolla, California 92093, USA. ${ }^{8}$ Department of Cardiology, Leiden University Medical Center, Albinusdreef 2, Leiden 2333 ZA, The Netherlands. ${ }^{9}$ Netherlands Organization for Applied Scientific Research-Metabolic Health Research, Gaubius Laboratory, Zernikedreef 9, Leiden 2333 CK, The Netherlands. * These authors contributed equally to this work. § These authors jointly supervised the work. Correspondence and requests for materials should be addressed to J.H. (email: heeren@uke.de) or to P.C.N.R. (email: p.c.n.rensen@lumc.nl).
} 
C ardiovascular diseases are the leading cause of morbidity and mortality in the Western world. Hyperlipidaemia, and in particular hypercholesterolaemia, is a major risk factor for the development of atherosclerosis, the main underlying cause of cardiovascular diseases. As current treatment strategies of atherogenic hyperlipidaemia prevent only $30 \%$ of all cardiovascular events ${ }^{1}$, novel treatment strategies are highly warranted.

Brown adipose tissue (BAT) is a highly active metabolic tissue that is present and active in adults ${ }^{2-7}$. Brown adipocytes not only reside in BAT depots but also lie scattered in certain white adipose tissue (WAT) depots. The development of these so-called peripheral, inducible brown adipocytes or 'beige/bright cells' is termed 'browning ${ }^{8,9}$. Both brown and beige adipocytes are functionally thermogenic and characterized by a large number of mitochondria and numerous small lipid droplets ${ }^{10}$. Physiologically, cold exposure activates BAT via stimulation of noradrenalin release by sympathetic neurons, which subsequently binds to $\beta 3$-adrenergic receptor ( $\beta 3$-AR) on the brown adipocyte membrane ${ }^{11}$. As the $\beta 3-A R$ is selectively found on brown and white adipocytes, and WAT does not substantially contribute to energy expenditure (EE), the cold-stimulated activation of brown adipocytes inducing thermogenesis can be pharmacologically mimicked by selective $\beta 3-\mathrm{AR}$ agonists such as CL316243, one the most selective $\beta 3$-AR agonists available ${ }^{11,12}$. However, cold exposure induces systemic hormonal changes and ultimately leads to marked adipose tissue remodelling, including proliferation and increased BAT mass. $\beta 3-\mathrm{AR}$ agonists, in contrast, along with inducing browning are only activating existing $\mathrm{BAT}^{11}$. As in cold exposure shivering thermogenesis is modulated and many other hormonal changes occur, $\beta 3-\mathrm{AR}$ agonists represent an excellent experimental tool to study the effects of BAT activation selectively. Activation of the $\beta 3$-AR on brown adipocytes rapidly induces intracellular lipolysis of triglycerides (TGs) from lipid droplets, resulting in release of fatty acids (FAs) into the cytoplasm. FAs are directed towards mitochondria where they either activate the uncoupling protein-1 (UCP1) in the inner membranes of mitochondria ${ }^{13}$ or undergo oxidation. The intracellular TG stores of brown adipocytes are rapidly replenished mainly by uptake of FA derived from lipolysis of TG-rich lipoproteins (TRLs) in the plasma ${ }^{14}$.

We showed that activation of BAT in mice via cold exposure $^{15,16}$ or metformin treatment ${ }^{17}$ potently reduces plasma TG levels and obesity. Therefore, activation of BAT is now considered a promising new therapeutic avenue to combat hypertriglyceridemia and obesity ${ }^{18,19}$. However, increased lipolytic processing of plasma TRL naturally accelerates formation of pro-atherogenic cholesterol-rich remnants as well, which are usually cleared by the liver. Thus, Dong et al. ${ }^{20}$ described that BAT activation by cold exposure aggravates hypercholesterolaemia and atherosclerosis development in Apoe ${ }^{-I-}$ and $L d l r^{-I-}$ mice, which are the most widely used atherosclerosis mouse models. Apolipoprotein E (ApoE) is an apolipoprotein mediating the clearance of remnant lipoproteins through interacting with hepatic lipoprotein receptors, including the low-density lipoprotein receptor (LDLR) ${ }^{21}$. Although Apoe ${ }^{-9}$ - mice predominantly display an accumulation of cholesterolenriched very-low-density lipoprotein (VLDL) remnants and very low high-density lipoprotein (HDL) levels ${ }^{22,23}, L_{d l}^{-1-}$ mice are characterized by high levels of remnant lipoproteins and LDL-cholesterol (LDL-C) without significant changes in HDL levels $^{24}$. It is likely to be that the enhanced clearance of plasma TGs on BAT activation may require efficient clearance of cholesterol-enriched lipoprotein remnants by the liver, a pathway that is considered to be crucially dependent on a functional apoE-LDLR axis ${ }^{21}$.
The APOE*3-Leiden.CETP (E3L.CETP) model is a wellestablished model for hyperlipidaemia and atherosclerosis, which, unlike Apoe $e^{-I-}$ and $L d l r^{-1-}$ mice, responds well to the lipidlowering and anti-atherogenic effects of statins ${ }^{25}$, fibrates ${ }^{26}$ and niacin ${ }^{27}$. E3L.CETP mice express a naturally occurring mutant form of human apoE3 that slows down remnant clearance, but does not completely abrogate the interaction with the $\mathrm{LDLR}^{28}$. This results in attenuated hepatic remnant clearance that is sufficient to induce hyperlipidaemia and atherosclerosis when feeding a Western-type diet (WTD), but, importantly, the hepatic remnant clearance route is still functional and can be modulated. In addition, E3L.CETP mice are transgenic for human cholesteryl ester transfer protein (CETP), which transfers cholesteryl esters from HDL to (V)LDL particles and for which rodents are naturally deficient. Hence, E3L.CETP mice are considered to display a more human-like lipoprotein metabolism.

Here we investigate the effects of $\beta 3$-AR-mediated BAT activation $^{12}$ on cholesterol metabolism and atherosclerosis development in E3L.CETP mice. Using TRL-mimicking particles, we show that the lipolytic conversion of TRLs by BAT increases the hepatic clearance of cholesterol-enriched lipoprotein remnants. This sequence of events results in a pronounced reduction in plasma TG and cholesterol levels, and ultimately in a marked attenuation of atherosclerosis development. In addition, we show that $A p o e^{-I-}$ and $L d l r^{-I-}$ mice do not respond to the plasma cholesterol-lowering activity of BAT and are not protected from atherosclerosis development, underlining the importance of the apoE-LDLR axis for the anti-atherogenic activity of BAT.

\section{Results}

Activation of BAT augments FA combustion. We first assessed the effect of BAT activation on EE and fat storage in female E3L.CETP mice fed an atherogenic WTD for 10 weeks, while being treated with the selective $\beta 3$-AR agonist CL316243 $(3 \times 20 \mu \mathrm{g}$ per mouse per week; subcutaneous) or vehicle (phosphate-buffered saline (PBS)). $\beta 3$-AR agonism tended to reduce body mass (up to $-8 \%$; Fig. 1a) and prevented total fat mass gain (up to $-81 \%$; Fig. 1b), without affecting lean mass (Fig. 1c) and cumulative food intake during the study (Fig. 1d). Accordingly, in the $\beta 3$-AR agonist-treated mice the weight of the individual WAT pads was lower (ranging from $-25 \%$ to $-52 \%$; Fig. 1e) and the average size of the lipid droplet within white adipocytes was smaller ( $-48 \%$; Fig. 1f,g).

The $\beta 3$-AR-mediated prevention of body fat gain was probably the consequence of increased adaptive thermogenesis, as total EE was markedly increased on the day of treatment $(+17 \%$; Fig. $2 a)$ without differences in activity levels (Fig. 2b). The increase in EE was confined to increased FA oxidation ( $+67 \%$; Fig. $2 \mathrm{c})$ rather than carbohydrate oxidation (Fig. 2d) and, consequently, $\beta 3$-AR agonism reduced the respiratory exchange ratio ( $-3.5 \%$; Fig. $2 \mathrm{e})$. This increased EE was accompanied by a marked activation of interscapular BAT (intBAT) as evidenced by reduced intracellular lipid vacuole size in intBAT ( $-87 \%$; Fig. 3a,b) and reduced weight of BAT pads (approximately $-25 \%$; Fig. 1e). UCP1 protein content per area of BAT was increased ( $+43 \%$; Fig. $3 c, d)$, but not when expressed per total fat pad (Fig. 3e), suggesting mainly the activation of existing BAT. In addition, $\beta 3-\mathrm{AR}$ agonism increased browning of WAT (Fig. 3f,g). These data combined thus show that $\beta 3$-AR agonism effectively activates BAT, enhances EE and increases browning of WAT under atherogenic conditions in E3L.CETP mice.

Activation of BAT increases hepatic VLDL remnant clearance. We next investigated the effect of BAT activation on plasma lipid levels in dyslipidemic E3L.CETP mice. BAT activation markedly 

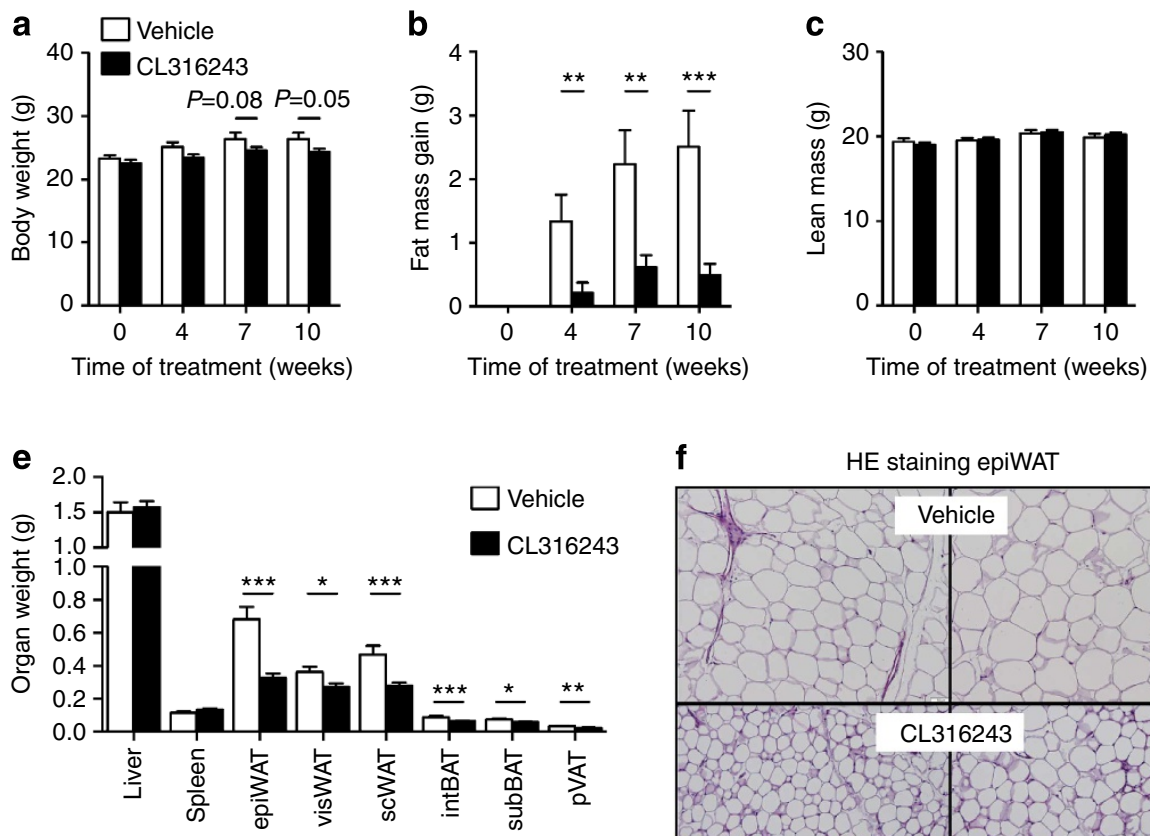

f

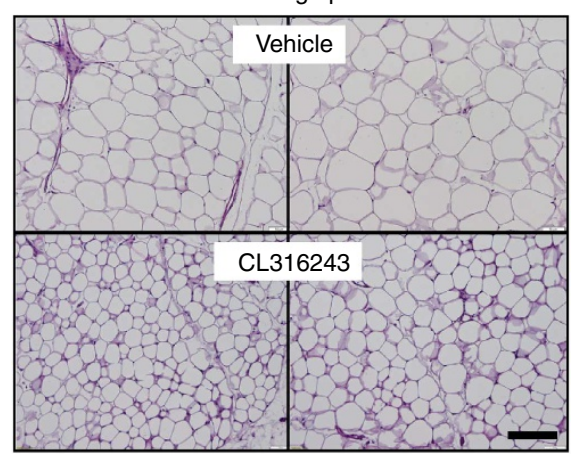

d

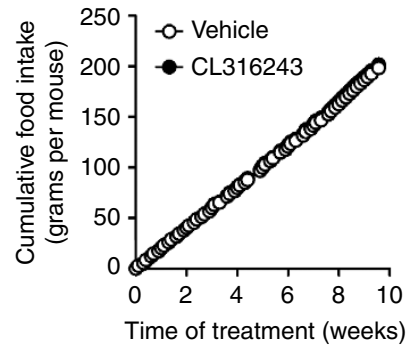

g

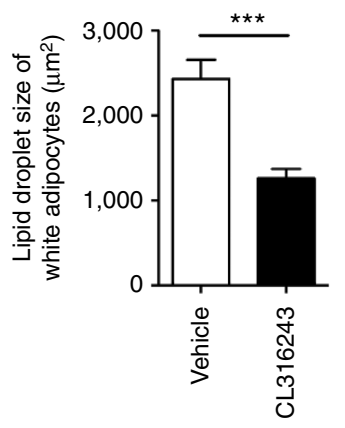

Figure 1 | $\mathbf{\beta 3 - A R}$ agonism reduces body fat mass in E3L.CETP mice. (a) Body weight, (b) gain of total body fat mass, (c) lean mass and (d) cumulative food intake were determined in WTD-fed E3L.CETP mice at the indicated time points during treatment with the $\beta 3$-AR agonist CL316243 or vehicle. (e) After necropsy at week 10, the weight of various organs was determined. (f) Epididymal WAT (epiWAT) was stained with haematoxylin-eosin (HE) and representative pictures are shown. Scale bar, $100 \mu \mathrm{m}$. (g) Lipid droplet size of white adipocytes was quantified. visWAT, visceral WAT; scWAT, subcutaneous WAT; intBAT, interscapular brown adipose tissue; subBAT, subscapular BAT; pVAT, perivascular adipose tissue. Values are means \pm s.e.m. (a-e: $n=13-19$ per group; $\mathbf{f}, \mathbf{g}: n=8$ per group). ${ }^{\star} P<0.05$, ${ }^{\star \star} P<0.01,{ }^{\star \star \star} P<0.001$ (unpaired two-tailed Student's $t$-test).

reduced plasma TG levels throughout the treatment period (approximately $-54 \%$; Fig. 4a), caused by a reduction in VLDLTG (Fig. 4b). Interestingly, BAT activation consistently reduced plasma total cholesterol (TC) levels (approximately -23\%; Fig. 4c), also confined to a reduction in the (V)LDL fraction (approximately $-27 \%$; Fig. 4d,e), without altering hepatic expression of genes relevant for lipid and lipoprotein metabolism (that is, Apob, CETP, Ldlr and Mttp; Supplementary Table 1). This lipid-lowering effect of CL316243-mediated brown fat activation did not differ from cold-induced effects, as cold exposure reduced hyperlipidaemia in E3L.CETP mice as well (Fig. 5a,b), despite a marked increase in dietary cholesterol intake in the cold (Fig. 5c).

We hypothesized that BAT activation reduces VLDL-TG as well as (V)LDL-C, as a result of enhanced uptake of TG-derived FA by BAT. Thus, the lipolytic processing of (V)LDL particles may lead to the formation of smaller cholesterol-enriched lipoprotein remnants, which are prone to be subsequently cleared by the liver. Therefore, we studied the in vivo plasma clearance and organ uptake of glycerol tri $\left[{ }^{3} \mathrm{H}\right]$ oleate (triolein, TO)- and $\left[{ }^{14} \mathrm{C}\right]$ cholesteryl oleate (CO)-double-labelled VLDL-mimicking particles (Fig. 6 and Supplementary Fig. 1) ${ }^{29}$ in E3L.CETP mice that were treated for 8 days with CL316243, which is compared with the long-term protocol (10 weeks as above) already sufficient to stimulate BAT activity and browning.

In vehicle-treated mice, the plasma decay of $\left[{ }^{3} \mathrm{H}\right] \mathrm{TO}$ (Fig. 6a) was faster than that of $\left[{ }^{14} \mathrm{C}\right] \mathrm{CO}$ (Fig. $6 \mathrm{c} ; t_{1 / 2}=2.9 \pm 0.1$ versus $4.7 \pm 0.5 \mathrm{~min}$; unpaired two-tailed Student's $t$-test, $P<0.01$ ), indicating that lipolytic processing and FA uptake precedes the clearance of core remnants. The uptake of $\left[{ }^{3} \mathrm{H}\right] \mathrm{TO}$-derived activity by the various BAT depots was much higher than by other metabolically active tissues (Fig. 6b). The uptake of ${ }^{3} \mathrm{H}$-activity by
BAT depots (Fig. 6b) was much larger than that of ${ }^{14} \mathrm{C}$-activity (Fig. 6d; average ratio ${ }^{3} \mathrm{H} /{ }^{14} \mathrm{C}=$ 'lipolysis index' $=11.1 \pm 0.9$ ), indicating selective uptake of $\left[{ }^{3} \mathrm{H}\right] \mathrm{TO}$-derived $\left[{ }^{3} \mathrm{H}\right]$ oleate rather than uptake of whole particles. Instead, the delipidated remnants were mainly taken up by the liver (Fig. 6b,d and Supplementary Fig. 1b; lipolysis index $=0.22 \pm 0.01$ ).

$\beta 3$-AR agonism markedly accelerated the plasma clearance of $\left[{ }^{3} \mathrm{H}\right] \mathrm{TO}\left(t_{1 / 2}=1.5 \pm 0.1\right.$ versus $2.9 \pm 0.1 \mathrm{~min}$; unpaired two-tailed Student's $t$-test, $P<0.001$; Fig. $6 \mathrm{a})$ and $\left[{ }^{14} \mathrm{C}\right] \mathrm{CO}\left(\mathrm{t}_{1 / 2}=3.3 \pm 0.3\right.$ versus $4.7 \pm 0.5 \mathrm{~min}$; Fig. $6 \mathrm{c}$ ). The accelerated clearance of $\left[{ }^{3} \mathrm{H}\right] \mathrm{TO}$ was explained by a pronounced increased uptake of $\left[{ }^{3} \mathrm{H}\right]$ oleate by the various BAT depots $(2-3$ fold; Fig. $6 \mathrm{~b}$ and Supplementary Fig. 1a), in accordance with increased BAT activity. The relative increase of $\left[{ }^{3} \mathrm{H}\right] \mathrm{TO}$ uptake into BAT is paralleled by $\left[{ }^{14} \mathrm{C}\right] \mathrm{CO}$ uptake, indicating that activation of BAT via $\beta 3$-AR agonism increases both FA and holoparticle uptake pathways to a similar extent. Interestingly, although the specific uptake by the WAT depots was still $\sim 15$-fold lower as compared with the BAT depots, $\beta 3$-AR agonism also increased the uptake of $\left[{ }^{3} \mathrm{H}\right]$ oleate by these WAT depots (2- to 3 -fold), possibly reflecting the activity of beige adipocytes within WAT. Concomitantly, BAT activation increased the uptake of $\left[{ }^{14} \mathrm{C}\right] \mathrm{CO}$ by the liver, by $\sim 25 \%$ (Fig. 6d and Supplementary Fig. 1b), indicating accelerated hepatic clearance of core remnants. The remnants that were generated by BAT activation and subsequently taken up by the liver were depleted from TG and more enriched in cholesterol as compared with remnants in vehicle-treated mice as indicated by an $\sim 30 \%$ reduction in lipolysis index $(0.15 \pm 0.01$ versus $0.22 \pm 0.01$; unpaired two-tailed Student's, $t$-test $P<0.01$; calculated from Fig. 6b,d).

Interestingly, additional univariate regression analyses showed that the uptake of TG-derived FA ( ${ }^{3} \mathrm{H}$ activity) by the various 

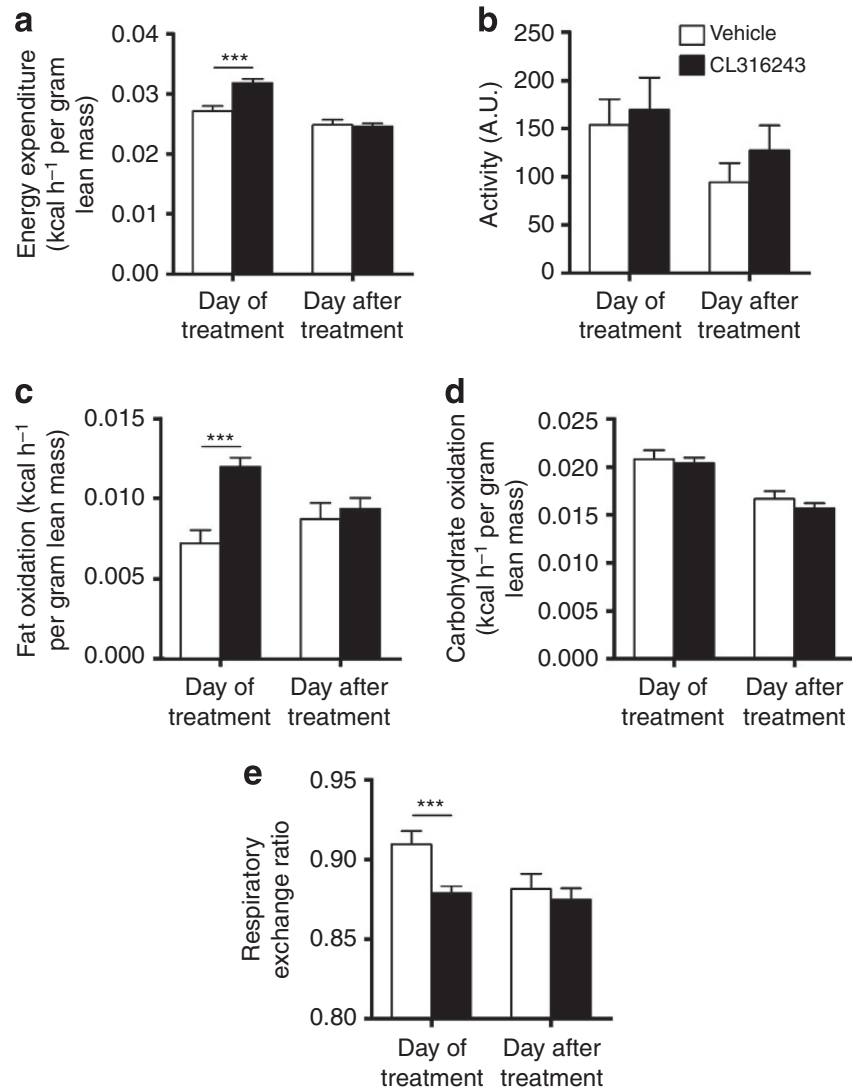

Figure 2 | 33 -AR agonism increases EE in E3L.CETP mice. (a) Mice were housed in fully automated metabolic cages and EE was determined and corrected for lean body mass. (b) Physical activity was monitored. In addition, (c) fat oxidation and (d) carbohydrate oxidation were determined and corrected for lean body mass. (e) Respiratory exchange ratio was determined. Data are shown as the first $12 \mathrm{~h}$ directly after the injection with CL316243 or vehicle ('Day of treatment') and the same 12-h period $24 \mathrm{~h}$ later ('Day after treatment'). Values are means \pm s.e.m. $(n=13-19$ per group). ${ }^{\star \star \star} P<0.001$ (unpaired two-tailed Student's $t$-test).

BAT depots predicted the uptake of the cholesterol-enriched remnants $\left({ }^{14} \mathrm{C}\right.$ activity) by the liver (Fig. 6e-g). This lipidlowering effect of $\beta 3$-AR agonism did not depend on CETP, as CL316243 also reduced plasma lipid levels in E3L mice without CETP (Fig. 7). Hence, BAT-mediated lipolytic processing of VLDL promotes the clearance of the corresponding cholesterolrich remnants by the liver.

Activation of BAT reduces atherosclerosis development. Next, we studied whether the decreased (V)LDL levels were accompanied by reduced atherosclerosis development. To this end, we determined atherosclerotic lesion area as well as severity and composition of the lesions in the root of the aortic arch after 10 weeks of BAT activation. Indeed, sustained BAT activation by $\beta 3$-AR agonism markedly reduced atherosclerotic lesion area throughout the aortic root (Fig. 8a,b), resulting in $43 \%$ lower mean atherosclerotic lesion area (Fig. 8c). BAT activation clearly reduced the severity of the lesions, as indicated by more mild lesions (that is, type I-III; +75\%) and less severe lesions (that is, type IV-V; $-38 \%$; Fig. 8d) without significantly affecting atherosclerotic lesion composition (that is, collagen, vascular smooth muscle cell and macrophage content of the lesions; Fig. $8 \mathrm{e}-\mathrm{g}$ ) or the lesion stability index (that is, ratio collagen/ macrophage area; Fig. $8 \mathrm{~h}$ ).
To evaluate the contribution of TG versus TC lowering to the reduction in atherosclerosis, univariate regression analyses were performed. To linearize data for analysis, the atherosclerotic lesion area was square root (SQRT) transformed ${ }^{27}$ and plotted against the TG and TC exposure (that is, area under the curve of plasma lipid for the complete treatment period). We found that the SQRT of the lesion area did not correlate with plasma TG exposure $\left(\beta=0.028 ; R^{2}=0.086 ; P=0.10\right.$; Fig. $\left.8 \mathrm{i}\right)$ but correlated with plasma TC exposure $\left(\beta=0.054 ; R^{2}=0.333 ; P<0.001\right.$; Fig. 8j). Additional univariate regression analyses showed that the (V)LDL-C exposure specifically predicts the SQRT of the lesion area $\left(\beta=0.055 ; R^{2}=0.358 ; P<0.001\right.$; Fig. $\left.8 \mathrm{k}\right)$. Taken together, these analyses reveal that a reduction in plasma (V)LDL-C is the main contributor to the anti-atherogenic effect of $\beta 3$-AR-mediated activation of BAT.

Anti-atherogenic effect depends on hepatic remnant clearance. As we observed increased hepatic uptake of lipoprotein remnants after CL316243-induced BAT activation (Fig. 6d), we evaluated the role of the apoE-LDLR axis, the main hepatic route for clearance of TRL remnants ${ }^{21}$. Cold adaptation ${ }^{20}$ and CL316243 treatment (data not shown) increased food intake in both $A p o e^{-I-}$ and $L d l r^{-I-}$ mice. Therefore, to match dietary cholesterol intake, we studied the effect of $\beta 3$-AR-mediated BAT activation in WTD-pair-fed Apoe ${ }^{-1-}$ mice and $L d l r^{-/-}$mice. Similar as in E3L.CETP mice, activation of BAT reduced body weight, WAT pad size and plasma TG levels (Fig. 9a and Supplementary Fig. 2a-c). However, activation of BAT did neither reduce plasma TC and (V)LDL-C levels (Fig. 9b and Supplementary Fig. 2d), change hepatic gene expression (Supplementary Table 1), nor did it reduce atherosclerosis development (Fig. 9c,d) in Apoe $e^{-I-}$ mice. As expected, the SQRT of the lesion area did not correlate with either total plasma TG exposure or plasma TC exposure during the study (Fig. 9e,f).

As the LDLR is the main hepatic clearance receptor for apoEcontaining lipoprotein remnants ${ }^{21}$, we next investigated the role of the LDLR for the (V)LDL-C-reducing effect of BAT activation. Similar as in E3L.CETP and Apoe $e^{-1-}$ mice, activation of BAT reduced body weight, WAT pad size and plasma TG levels in WTD-pair-fed Ldlr-I- mice (Fig. $9 \mathrm{~g}$ and Supplementary Fig. $3 \mathrm{a}-\mathrm{c})$. However, activation of BAT in $\mathrm{Ldlr}^{-I^{-}}$mice did neither reduce plasma TC and (V)LDL-C levels (Fig. 9h and Supplementary Fig. 3d), change messenger RNA levels of selected hepatic genes (Supplementary Table 1), nor reduce atherosclerosis development (Fig. 9i,j), nor did the SQRT of the lesion area correlate with the total plasma TG and TC exposure during the study (Fig. 9k,l). Taken together, these findings demonstrate that activation of BAT reduces plasma (V)LDL-C and subsequently reduces atherosclerosis development through enhanced LDLR-mediated hepatic clearance of apoE-containing lipoprotein remnants.

\section{Discussion}

Since its rediscovery in human adults in the last decade ${ }^{2,4-7,30}$, BAT has been considered a promising therapeutic target for obesity and associated metabolic disorders. The anti-obesity potential of BAT has been irrefutably proven in murine studies $^{18,19,31}$ and shown in human studies ${ }^{4,30,32,33}$. However, in light of the study by Dong et al. ${ }^{20}$, the effect of BAT activation on cholesterol metabolism and atherosclerosis development remained controversial to date. Here we present evidence that, in principle, BAT activation is beneficial and not deleterious for plasma cholesterol metabolism and atherosclerosis development. Using E3L.CETP and E3L mice, we demonstrate that 
a

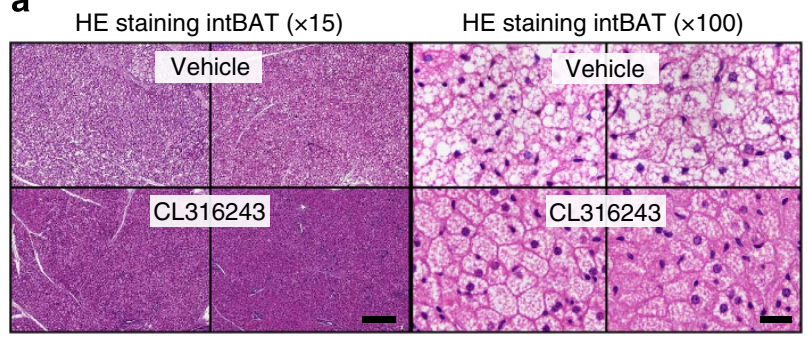

b

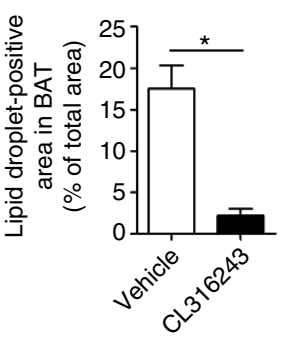

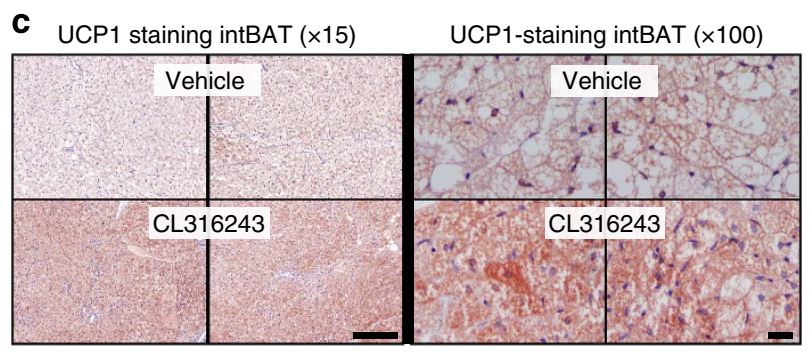

d

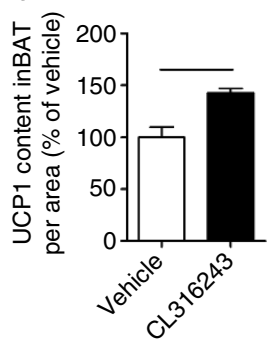

e

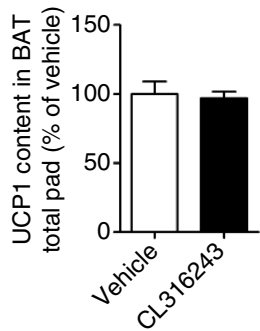

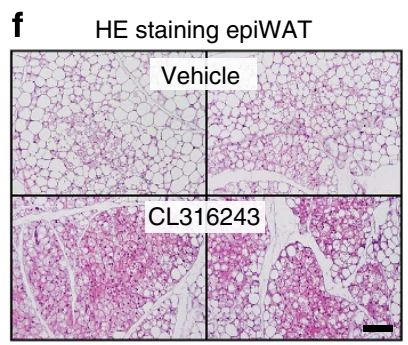

g

UCP1 staining epiWAT

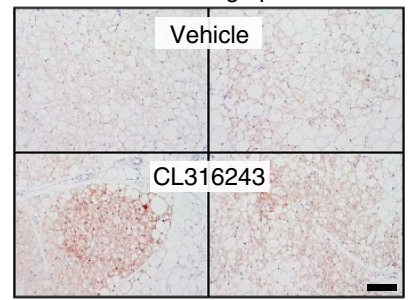

Figure 3 | $\mathbf{3 3 - A R}$ agonism activates BAT and increases browning of WAT in E3L.CETP mice. Slides of intBAT of $\beta 3-A R$ agonist CL316243- and vehicle-treated E3L.CETP mice were (a) stained with haematoxylin-eosin (HE) or (c) immunohistochemically stained for UCP1, and representative pictures are shown. Scale bar, $200 \mu \mathrm{m}$ (for $\times 15$ original magnification) and $20 \mu \mathrm{m}$ (for $\times 100$ original magnification). (b) Lipid droplet-positive area, (d) UCP1 content per area and (e) UCP1 content of the total fat pad were quantified. Slides of epidydimal WAT (epiWAT) were stained with (f) HE and (g) immunohistochemically stained for UCP1, and representative pictures are shown. Scale bar, $100 \mu \mathrm{m}$. Values are means \pm s.e.m. ( $n=8$ per group). ${ }^{\star} P<0.05,{ }^{\star \star} P<0.01$ (unpaired two-tailed Student's $t$-test).
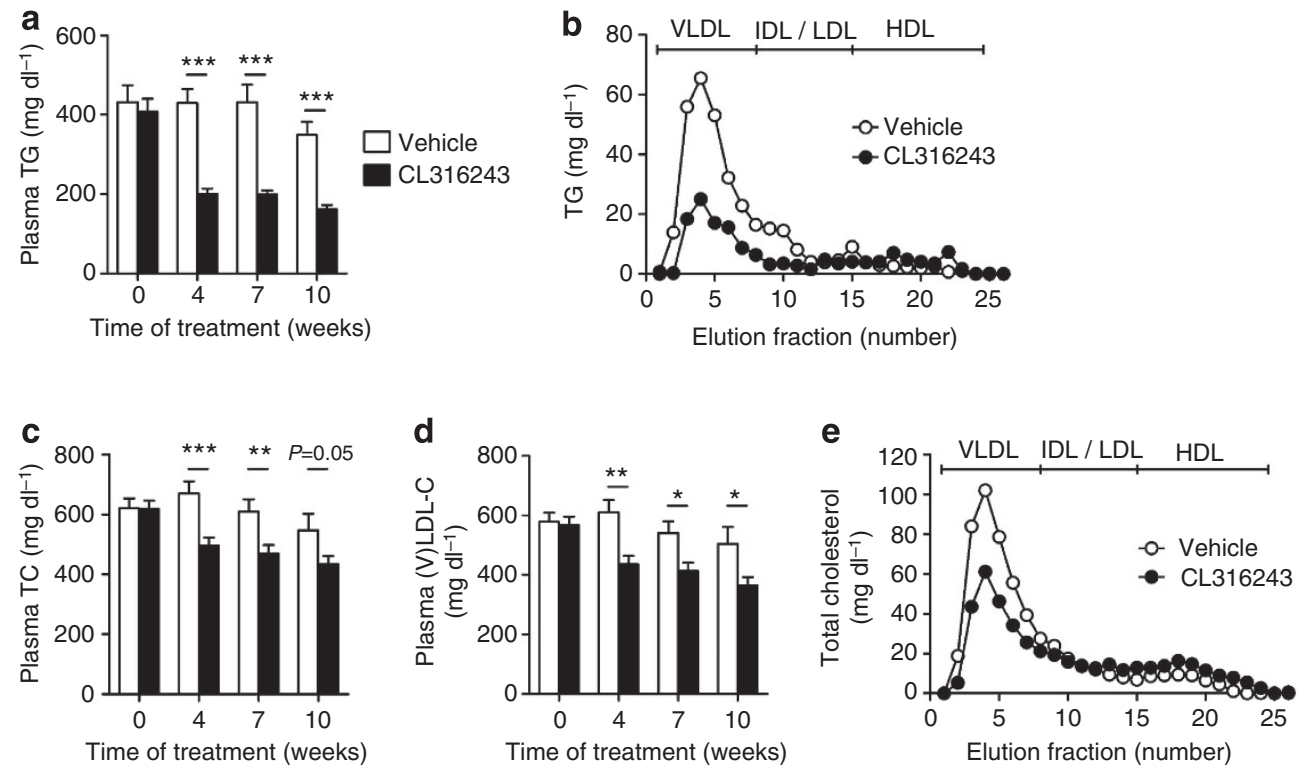

Figure 4 | $\mathbf{\beta 3 - A R}$ agonism ameliorates dyslipidemia in E3L.CETP mice. Fasting plasma (a) TG, (c) TC and (d) VLDL-C were measured in WTD-fed E3L.CETP at the indicated time points during treatment with the $\beta 3-A R$ agonist CL316243 or vehicle. The distribution of (b) TG and (e) TC over lipoproteins was determined after 10 weeks of treatment on pooled plasma samples per group. Values are means \pm s.e.m. $\left(n=13-19\right.$ per group or pool). ${ }^{\star} P<0.05$, ${ }^{\star \star} P<0.01,{ }^{\star \star \star} P<0.001$ (unpaired two-tailed Student's $t$-test). 

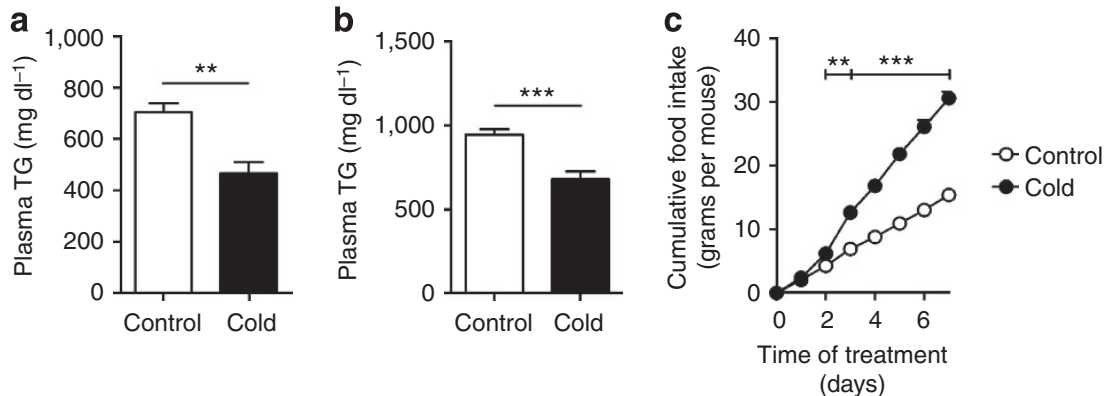

Figure 5 | Cold exposure decreases dyslipidemia in E3L.CETP mice. E3L.CETP mice were fed a WTD and exposed to cold or control temperature for 7 days. Fasted plasma (a) TG and (b) TC were determined at the end of treatment. (c) Mice were individually housed and cumulative food intake was determined during treatment. Values are means \pm s.e.m. ( $n=8$ per group). ${ }^{\star \star} P<0.01,{ }^{\star \star \star} p<0.001$ (unpaired two-tailed Student's $t$-test).
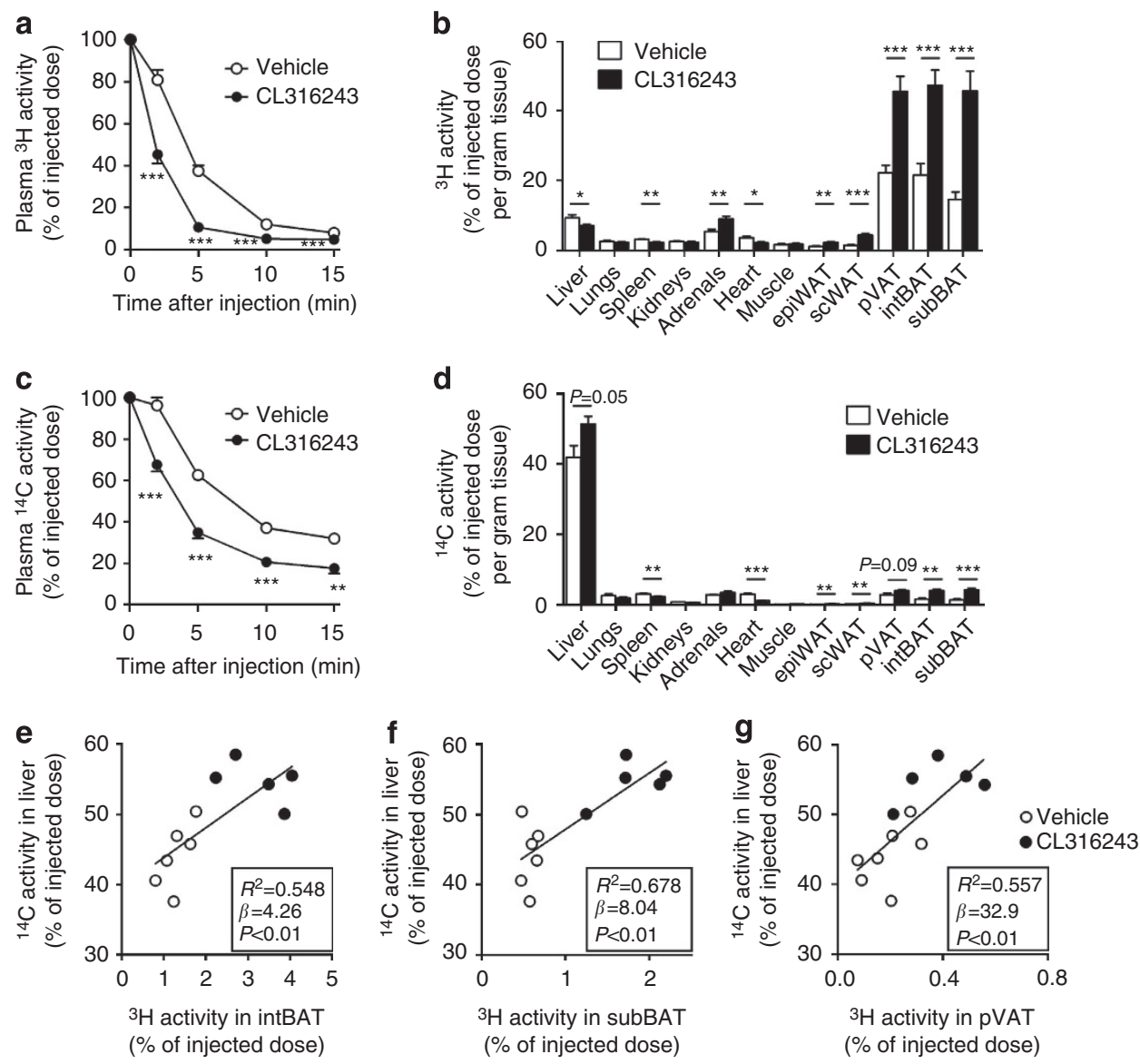

Figure 6 | B3-AR agonism increases lipolytic processing and hepatic clearance of lipoproteins in E3L.CETP mice. $\beta 3$-AR agonist CL316243- and vehicle-treated mice were injected with VLDL-like particles, double-labelled with glycerol $\left[{ }^{3} \mathrm{H}\right] \mathrm{TO}$ and $\left[{ }^{14} \mathrm{C}\right] \mathrm{CO}$, and $(\mathbf{a}, \mathbf{c})$ clearance from plasma as well as (b,d) uptake by organs and tissues at $15 \mathrm{~min}$ after injection were determined for $(\mathbf{a}, \mathbf{b}){ }^{3} \mathrm{H}$-activity and $(\mathbf{c}, \mathbf{d}){ }^{14} \mathrm{C}$-activity. The hepatic uptake of ${ }^{14} \mathrm{C}$ activity was plotted against the uptake of $\left[{ }^{3} \mathrm{H}\right]$ TO-derived activity in (e) interscapular brown adipose tissue (intBAT), (f) subscapular BAT (subBAT) and (g) perivascular adipose tissue (pVAT). Linear regression analyses were performed. Values are means \pm s.e.m. $\left(n=5-7\right.$ per group). ${ }^{\star} P<0.05,{ }^{\star \star} P<0.01$, ${ }^{\star \star \star} P<0.001$ (unpaired two-tailed Student's $t$-test).

BAT-mediated local lipolysis of TG-rich lipoproteins stimulated hepatic clearance of lipoprotein remnants via a pathway involving the apoE-LDLR pathway. As a result, BAT activation reduced atherosclerotic lesion size and severity in E3L.CETP mice but not in mice lacking either apoE or LDLR.

Our study indicates that the ability of the liver to clear apoEenriched lipoprotein remnants via the LDLR is a prerequisite for the anti-atherogenic potential of BAT activation. According to this view, it is not surprising that Dong et al. ${ }^{20}$ recently observed that BAT activation by cold exposure in Apoe $e^{-1-}$ and $L d l r^{-1-}$ mice actually increased plasma (V)LDL-C levels and atherosclerosis. Likewise, in these hyperlipidemic mouse models prolonged BAT activation results in lipoprotein remnant levels in plasma exceeding the hepatic clearance capacity. In fact, Dong et $a .^{20}$ did show that activation of BAT by cold in normolipidemic wild-type C57Bl/6 mice actually decreased 
plasma TC and (V)LDL-C levels, which is in full accordance with a functional hepatic apoE-LDLR clearance route of lipoprotein remnants in wild-type mice. It is also reasonable that in mice
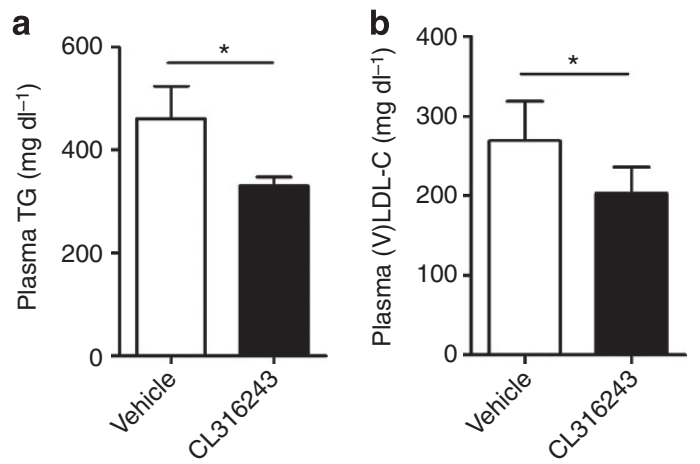

Figure 7 | $\beta 3-A R$ agonism reduces dyslipidemia in E3L mice in the absence of CETP. E3L mice were fed a WTD and treated with vehicle or the B3-AR agonist CL316243. Fasted plasma (a) TG and (b) (V)LDL-C were determined. Values are means \pm s.e.m. $\left(n=5-7\right.$ per group). ${ }^{\star} P<0.05$ (unpaired two-tailed Student's $t$-test). lacking UCP1 in addition to apoE or LDLR, the formation of remnants is impaired, thereby apparently paradoxically protecting these mice from atherosclerosis ${ }^{20}$. As we observe that both CL316243 treatment (Fig. 4) and cold exposure (Fig. 5a,b) reduce hyperlipidaemia in E3L.CETP mice our results provide proof for the concept that in principle BAT activation has beneficial effects on plasma lipids.

In this study, we used TRL-mimicking particles as models for TRLs. We previously showed that these particles rapidly acquire an array of exchangeable apolipoproteins from serum, including apoE, apoCs, apoAIV, apoAI, apoAII and apoD 29,34 , and that the hepatic uptake of their core remnants is mediated by $\operatorname{apoE}^{34}$. In fact, the in-vivo kinetics of $\left[{ }^{3} \mathrm{H}\right]$ cholesteryl oleate-labelled TRL-mimicking particles ${ }^{34}$ are very similar to those of $\left[{ }^{3} \mathrm{H}\right]$ vitamin A-labelled native chylomicrons ${ }^{35}$, with similar clearance rate from plasma $\left(t_{1 / 2} \sim 2 \mathrm{~min}\right)$ and uptake by the liver $(\sim 65 \%-75 \%$ after $30 \mathrm{~min})$. Lactoferrin reduced the uptake by the liver of both TRL-mimicking particles and chylomicrons by $\sim 75 \%{ }^{35}$ and liver cell distribution studies confirmed that hepatocytes accounted for $\sim 75 \%$ of the total uptake by the liver ${ }^{35}$. Taken together, it is likely to be that the present findings with TRL-mimicking particles can be translated to endogenous TLRs.
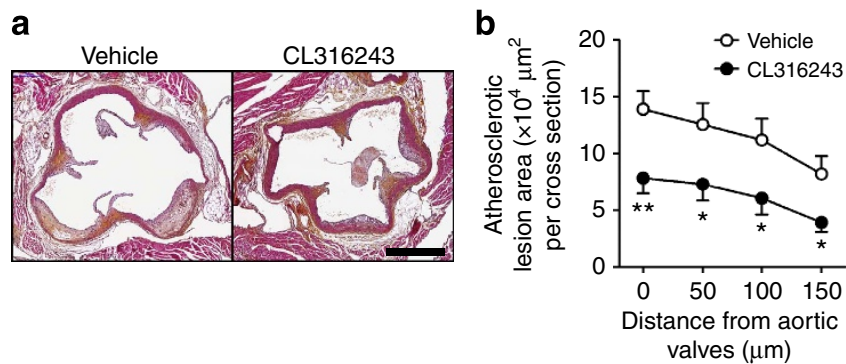
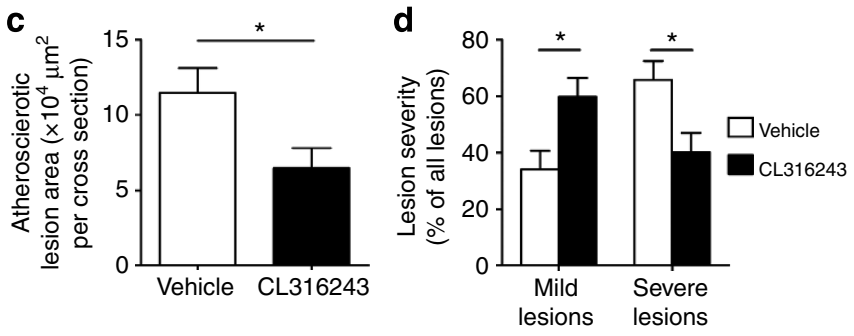
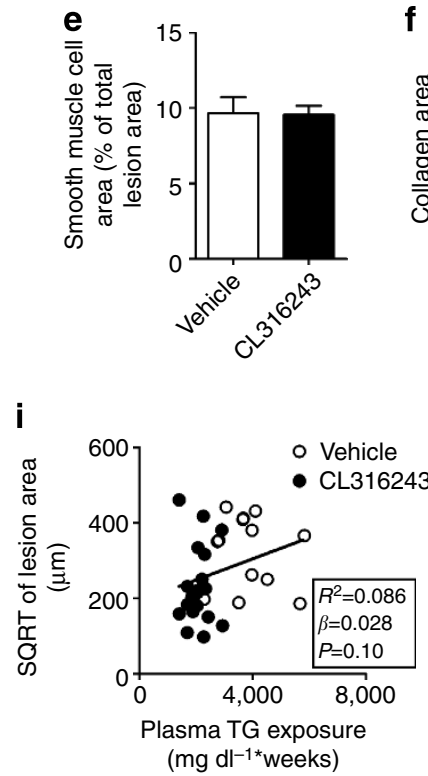
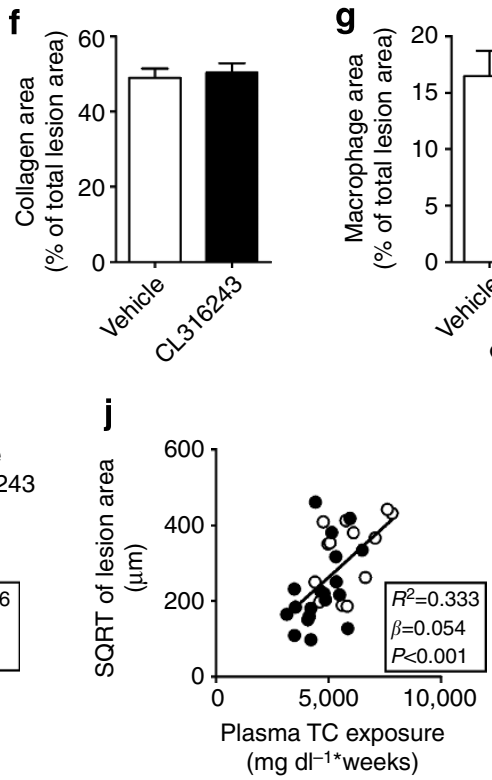
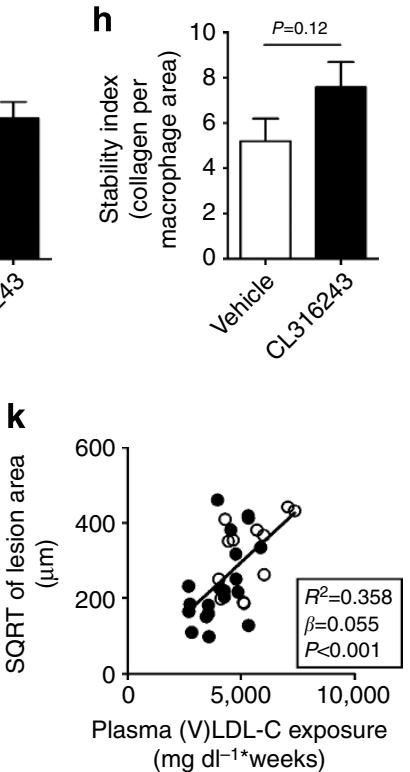

Figure 8 | BAT activation reduces atherosclerosis by improving the plasma cholesterol profile. (a) Slides of the valve area of the aortic root of $\beta 3-A R$ agonist CL316243- and vehicle-treated E3L.CETP mice were stained with haematoxylin-phloxine-saffron and representative pictures are shown. Scale bar, $400 \mu \mathrm{m}$. (b) Lesion area as a function of distance was determined per mouse, starting from the appearance of open aortic valve leaflets covering $150 \mu \mathrm{m}$. (c) The mean atherosclerotic lesion area was determined from the four cross-sections from $\mathbf{b}$ and (d) lesions were categorized according to lesion severity. (e) The smooth muscle cell, (f) collagen and (g) macrophage content of the lesions were determined, and (h) the stability index (collagen/macrophage content of the lesions) was calculated. The SQRT of the atherosclerotic lesion area from $\mathbf{b}$ was plotted against the plasma (i) total TG, (j) TC and (k) $(\mathrm{V}) \mathrm{LDL}-\mathrm{C}$ exposure during the 10-week treatment period. Linear regression analyses were performed. Values are means $\pm \mathrm{s} . \mathrm{e} . \mathrm{m}$. ( $n=13-19$ per group). ${ }^{\star} P<0.05,{ }^{\star \star} P<0.01$ (b-h: unpaired two-tailed Student's $t$-test). 


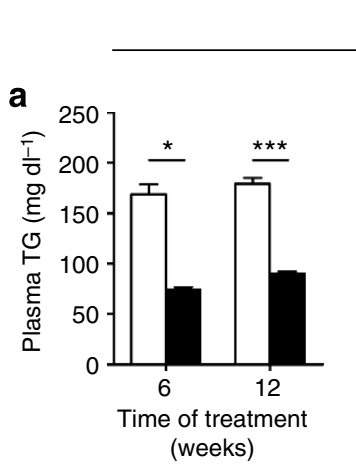

c

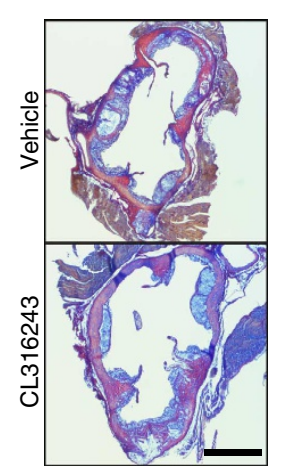

e

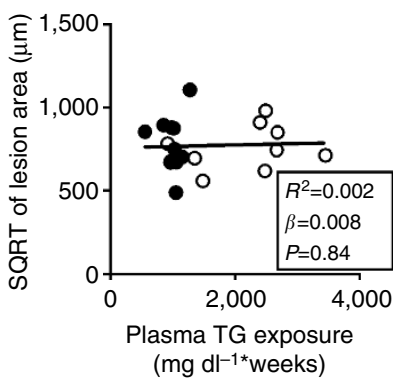

Apoe $^{-/-}$

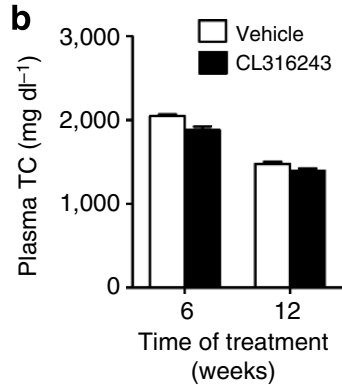

d

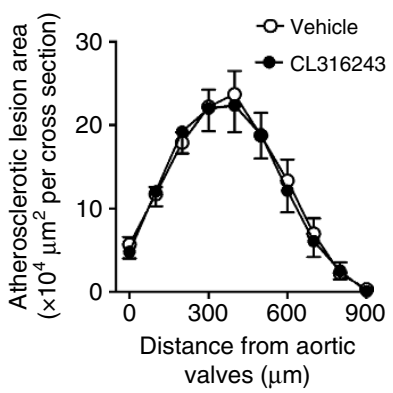

f

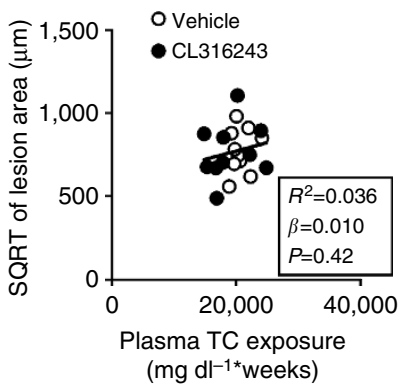

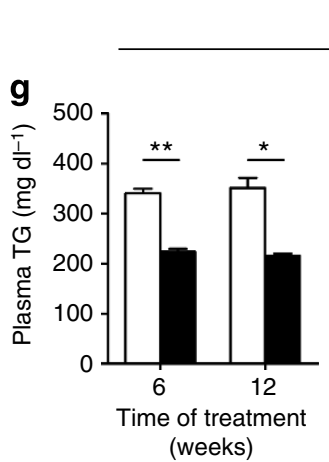

$L d l r^{-/-}$
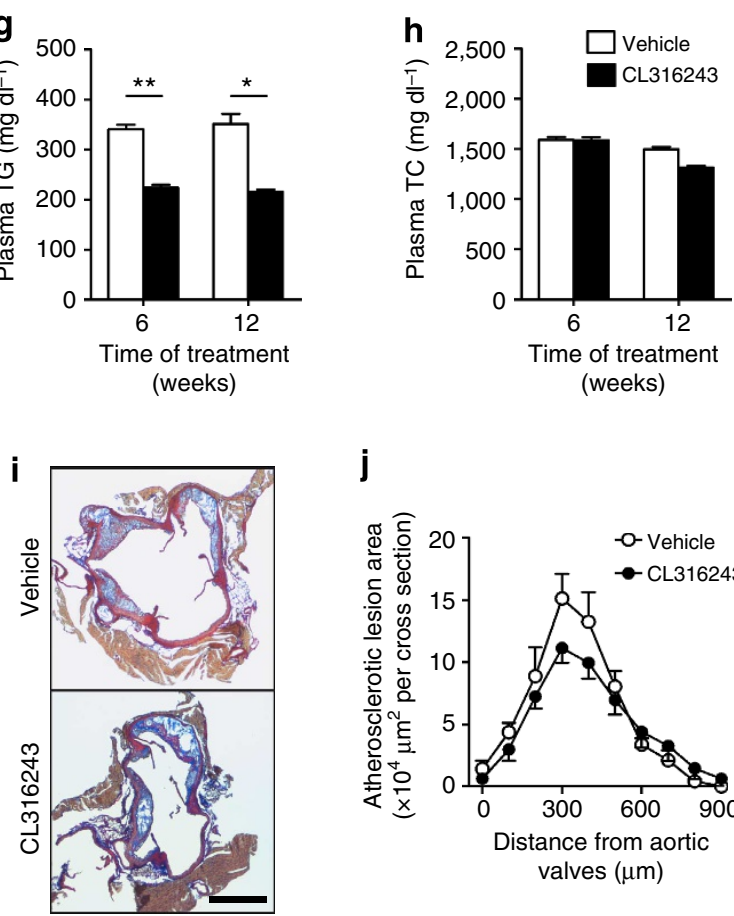

j

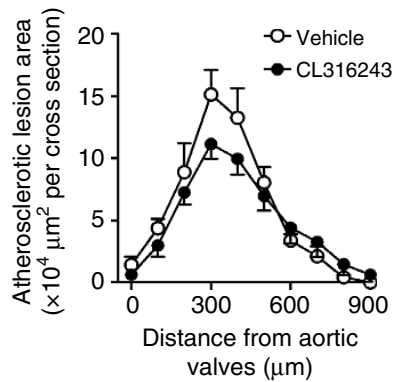

$\mathbf{k}$

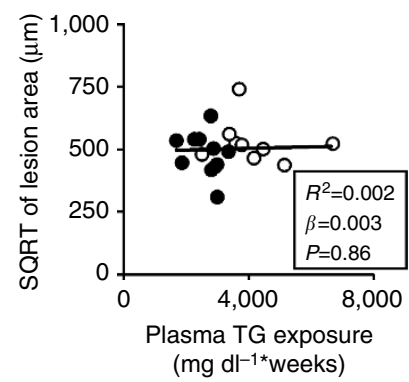

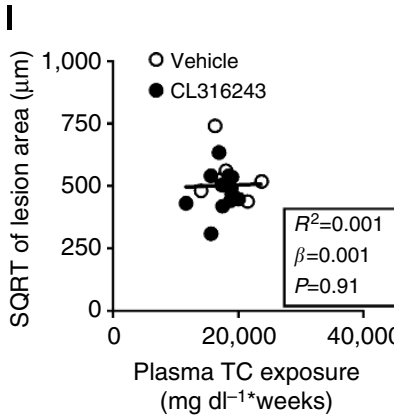

Figure 9 | BAT activation in Apoe $\mathbf{A}^{-/}$and $\mathbf{L d I r}^{-/}$- mice reduces plasma TG, but not TC nor atherosclerosis. Fasting plasma (a) TG and (b) TC levels were measured in WTD-fed Apoe ${ }^{-/-}$mice at the indicated time points during treatment with the $\beta 3-A R$ agonist CL316243 or vehicle. (c) Slides of the valve area of the aortic root of CL316243- or vehicle-treated Apoe ${ }^{-/-}$mice were stained with modified Van Gieson stain and representative pictures are shown. Scale bar, $400 \mu \mathrm{m}$. (d) Lesion area as a function of distance was determined per mouse starting from the appearance of open aortic valve leaflets covering $900 \mu \mathrm{m}$. The SQRT of the atherosclerotic lesion area from $\mathbf{d}$ in $A p o e^{-/-}$mice was plotted against the plasma (e) total TG and (f) TC exposure during the 12-week treatment period. Linear regression analyses were performed. Fasting plasma (g) TG and (h) TC levels were measured in WTD-fed $\mathrm{Ldll}^{-/}-$mice at the indicated time points during treatment with the $\beta 3$-AR agonist CL316243 or vehicle. (i) Slides of the valve area of the aortic root of CL316243- or vehicle-treated $L d l^{-1}{ }^{-1}$ mice were stained with modified Van Gieson stain and representative pictures are shown. Scale bar, $400 \mu \mathrm{m}$. (j) Lesion area as a function of distance was determined per mouse starting from the appearance of open aortic valve leaflets covering $900 \mu \mathrm{m}$. The SQRT of the atherosclerotic lesion area from $\mathbf{j}$ in $\mathrm{Ldll}^{-/}{ }^{-}$mice was plotted against the plasma (k) total TG and (I) TC exposure during the 12-week treatment period. Linear regression analyses were performed. Values are means \pm s.e.m. $\left(n=8-11\right.$ per group or pool). ${ }^{\star} P<0.05,{ }^{\star \star} P<0.01,{ }^{\star \star \star} P<0.001$ $(\mathbf{a}, \mathbf{b}, \mathbf{d}, \mathbf{g}, \mathbf{h}, \mathbf{j}:$ unpaired two-tailed Student's t-test).

Our work sets the foundation for future studies that investigate the anti-atherogenic potential of BAT in humans, especially since a recent study demonstrated that $\beta 3$-AR agonism activates BAT and increases EE in humans ${ }^{36}$. As the discovery that functional BAT is present and active in human adults was made only in the last decade ${ }^{2,4-7,30}$, recent studies have focused on the physiological relevance of BAT for humans. The concept of BAT being involved in energy metabolism and being a target for obesity was appreciated some decades ago based on experimental studies in rodents ${ }^{37,38}$. More recently, its role in human energy metabolism and obesity development became apparent as well, from observations that BAT activity inversely correlates with obesity $^{39}$, and that cold acclimation recruits $\mathrm{BAT}^{40}$ and lowers fat mass $^{33}$. In addition, South Asians, who have a high susceptibility to metabolic disorders, have decreased $\mathrm{EE}$ associated with decreased BAT volume and activity compared with white Caucasians, although it should be noted that body composition is different between these ethnicities ${ }^{41}$. Importantly, BAT activation by means of cold acclimation also improved cholesterol metabolism in human patients with hypercholesterolaemia $^{42}$, underscoring the potential of BAT activation as a potential anti-atherogenic treatment in humans.

In conclusion, our data demonstrate that activation of BAT lowers atherogenic lipoprotein levels and protects against 
atherosclerosis development. Moreover, we show the importance of a functional hepatic apoE-LDLR clearance pathway, rendering Apoe $e^{-1-}$ or $\mathrm{Ldlr}^{-1-}$ mice inappropriate models for studying the beneficial effects of BAT modulation on plasma cholesterol metabolism and atherosclerosis development. We propose that BAT activation, resulting in accelerated generation of lipoprotein remnants, should preferentially be combined with strategies that increase hepatic LDLR expression, including statins and/or proprotein convertase subtilisin/kexin type 9 blockers, thus fully unravelling the therapeutic potential of BAT for atherosclerosis prevention and treatment.

\section{Methods}

Mice and animal procedures. Female $E 3 L$ were cross-bred with mice expressing human CETP under control of its natural flanking regions, to generate heterozygous E3L.CETP mice ${ }^{25}$. Female E3L.CETP and E3L mice were 10-12 weeks of age and individually housed under standard conditions with a 12-h light-dark cycle, free access to food and water, and $22^{\circ} \mathrm{C}$ room temperature. Mice were fed a WTD (HopeFarms, Woerden, The Netherlands) supplemented with $0.1 \%$ cholesterol and treated with the $\beta 3$-AR agonist CL316243 (Tocris Bioscience Bristol, UK; $3 \times 20 \mu$ g per mouse per week; subcutaneous) or vehicle (PBS) for 10 weeks. Food intake and body weight, as well as total body fat and lean mass, were monitored by EchoMRI-100 (EchoMRI, Houston, Texas) during the studies.

Male Apoe $e^{-1-}$ and $L d l r^{-1-}$ mice (Jackson Laboratory, Bar Harbor, ME) were individually housed and fed a WTD supplemented with $0.2 \%$ cholesterol with or without CL316243 (0.001\% w/w). As CL316243 treatment of Apoe $e^{-I-}$ and $L d r^{-I}-$ mice increased food intake, these mice were pair-fed to their respective controls after onset of effect. All animal experiments were approved by the Ethics Committee on Animal Care and Experimentation of the Leiden University Medical Center or The Animal Welfare Committee of University Medical Center Hamburg-Eppendorf.

Indirect calorimetry. Indirect calorimetry was performed in fully automatic metabolic cages (LabMaster System, TSE Systems, Bad Homburg, Germany) during the ninth week of treatment. After 1 day of acclimatization, $\mathrm{O}_{2}$ consumption, $\mathrm{CO}_{2}$ production and caloric intake were measured for 3 consecutive days ${ }^{42}$. Total EE was estimated from the $\mathrm{VO}_{2}$ and resting energy requirement. Carbohydrate oxidation was calculated using the formula $\left(\left(4.585^{\star} \mathrm{VCO}_{2}\right)-\left(3.226^{*} \mathrm{VO}_{2}\right)\right)^{*} 4$, in which the 4 represents the conversion from mass per time unit to kcal per time unit ${ }^{43}$. Similarly, fat oxidation was calculated using the formula $\left(\left(1.695^{*} \mathrm{VO}_{2}\right)-\left(1.701^{\star} \mathrm{VCO}\right)\right)^{\star} 9$.

Values were normalized to lean mass. Physical activity was monitored using infrared sensor frames. The first $12 \mathrm{~h}$ directly after injection with CL316243 or vehicle ('Day of treatment') were analysed and compared with the same 12 -h period $24 \mathrm{~h}$ later ('Day after treatment').

Cold exposure. Mice were individually housed with ad libitum access to WTD and water during exposure to $4{ }^{\circ} \mathrm{C}$ in a cold room with a 12 -h light-dark cycle. After 7 days of cold exposure $4 \mathrm{~h}$-fasted plasma lipids were determined as described below.

In-vivo plasma decay and organ uptake of VLDL-like particles. VLDL-like TGrich emulsion particles $(80 \mathrm{~nm})$ labelled with glycerol tri $\left[{ }^{3} \mathrm{H}\right]$ oleate $(\mathrm{TO})$ and $\left.{ }^{14} \mathrm{C}\right] \mathrm{CO}$ were prepared and characterized as described previously ${ }^{29}$. Briefly, $\left[{ }^{3} \mathrm{H}\right] \mathrm{TO}(100 \mu \mathrm{Ci})$ and $\left[{ }^{14} \mathrm{C}\right] \mathrm{CO}(10 \mu \mathrm{Ci})$ tracers were added to a mixture of TO (70 mg), egg yolk phosphatidylcholine $(22.7 \mathrm{mg})$, lysophosphatidylcholine $(2.3 \mathrm{mg})$, $\mathrm{CO}(3.0 \mathrm{mg})$ and cholesterol $(2.0 \mathrm{mg})$. Particles were prepared from this mixture at $54{ }^{\circ} \mathrm{C}$ using a Soniprep 150 (MSE Scientific Instruments, UK) at $10 \mu \mathrm{m}$ output. The emulsion was fractionated by consecutive density gradient ultracentrifugation steps in a Beckman SW 40 Ti rotor. After centrifugation ( $27 \mathrm{~min}, 20,000$ r.p.m., $\left.20^{\circ} \mathrm{C}\right)$ the top fraction containing chylomicron-like particles with an average size of $150 \mathrm{~nm}$ was discarded. After a subsequent centrifugation step (27 min, 40,000 r.p.m., $20^{\circ} \mathrm{C}$ ) VLDL-like particles with an average size of $80 \mathrm{~nm}$ were isolated, stored at $4{ }^{\circ} \mathrm{C}$ under argon and used within 5 days.

After 8 days of treatment with the $\beta 3$-AR agonist CL316243 (20 $\mu \mathrm{g}$ per mouse per day) mice were fasted for $4 \mathrm{~h}$ and injected $(t=0)$ via the tail vein with the emulsion particles $(1.0 \mathrm{mg}$ TG per mouse in $200 \mu \mathrm{l}$ PBS). Blood samples were taken from the tail vein at 2, 5,10 and 15 min after injection, to determine the plasma decay of $\left[{ }^{3} \mathrm{H}\right] \mathrm{TO}$ and $\left[{ }^{14} \mathrm{C}\right] \mathrm{CO}$. Plasma volumes were calculated as $0.04706 \times$ body weight $(\mathrm{g})$ as determined from ${ }^{125} \mathrm{I}$-labelled BSA clearance studies as described ${ }^{44}$. After $15 \mathrm{~min}$, mice were killed by cervical dislocation and perfused with ice-cold heparin solution $(0.1 \% \mathrm{v} / \mathrm{v}$ in PBS) via the heart, to remove blood from the organs and tissues. Subsequently, organs and tissues were isolated, dissolved overnight at $56^{\circ} \mathrm{C}$ in Tissue Solubilizer (Amersham Biosciences, Rosendaal, The Netherlands) and quantified for ${ }^{3} \mathrm{H}$ and ${ }^{14} \mathrm{C}$ activity. Uptake of $\left[{ }^{3} \mathrm{H}\right] \mathrm{TO}-$ and $\left[{ }^{14} \mathrm{C}\right] \mathrm{CO}$-derived radioactivity by the organs and tissues was expressed per gram wet tissue weight or calculated as dose per organ after correction for organ weight.
Plasma parameters and lipoprotein profiles. Blood was collected from the tail vein of 4-h fasted mice into EDTA- (E3L.CETP and E3L mice) or lithium-heparincoated tubes (Apoe $e^{-l-}$ and $L d l r^{-1-}$ mice). Tubes were placed on ice, centrifuged and plasma was isolated and assayed for TG and TC by using commercially available enzymatic kits from Roche Diagnostics (Mannheim, Germany). Plasma (V)LDL-C levels were calculated by extraction of HDL-C from TC levels. HDL-C levels were determined by precipitating apoB-containing lipoproteins from plasma by addition of $20 \%$ polyethylene glycol in $200 \mathrm{mM}$ glycine buffer with $\mathrm{pH} 10$ and TC was measured in the supernatant as described above. The distribution of TG and cholesterol over lipoproteins was determined in pooled plasma by fast-performance liquid chromatography on a Superose 6 column (GE Healthcare, Piscataway, NJ).

Hepatic gene expression analysis. Total RNA was extracted from snap-frozen livers using Tripure RNA isolation reagent (Roche, Mijdrecht, The Netherlands), according to the manufacturer's instructions. Complementary DNA for quantitative reverse transcriptase-PCR was produced by reverse transcription of total RNA using Moloney Murine Leukemia Virus Reverse Transcriptase (Promega, Leiden, The Netherlands). mRNA expression was normalized to $\beta 2$-microglobulin and $36 b 4$ mRNA content and expressed as fold change compared with control mice. The primer sequences used are listed in Supplementary Table 2.

Necropsy and histology of BAT and WAT. At the end of the study, mice were anaesthetized by intraperitoneal injection of acepromazine $\left(6.25 \mathrm{mg} \mathrm{kg}^{-1}\right.$. Alfasan, Woerden, The Netherlands), midazolam $\left(0.25 \mathrm{mg} \mathrm{kg}^{-1}\right.$; Roche, Mijdrecht, The Netherlands) and fentanyl $\left(0.31 \mathrm{mg} \mathrm{kg}^{-1}\right.$; Janssen-Cilag, Tilburg, The Netherlands), bled and killed by cervical dislocation or transcardial blood withdrawal. The blood circulation was perfused with ice-cold heparin solution $(0.1 \% \mathrm{v} / \mathrm{v}$ in PBS), and organs and tissues were weighed and collected for further analyses. Epididymal WAT and intBAT were removed and preserved in phosphate-buffered $4 \%$ formaldehyde and embedded in paraffin. Haematoxylin-eosin staining was performed using standard protocols. Intracellular lipid droplet size in WAT and percentage of lipid-droplet-positive area in BAT were quantified using Image J software (version 1.47).

For UCP1 staining, 5- $\mu \mathrm{m}$ sections were deparafinnized in xylene, rehydrated in ethanol and treated with $3 \% \mathrm{H}_{2} \mathrm{O}_{2}$ (Sigma-Aldrich, Zwijndrecht, The Netherlands) in absolute methanol for $30 \mathrm{~min}$, to block endogenous peroxidase activity. Sections were immersed in citrate buffer $(10 \mathrm{mM}, \mathrm{pH}$ 6) and boiled for $10 \mathrm{~min}$. Slides were blocked with $1.3 \%$ normal goat serum (in PBS) and incubated overnight at $4{ }^{\circ} \mathrm{C}$ with rabbit monoclonal anti-UCP1 antibody (Abcam, Cambridge, UK; 1:400 in 1.3\% normal goat serum). Subsequently, sections were incubated for 60 min with biotinylated goat $\alpha$-rabbit secondary antibody (Vector Labs, Burlingame, CA) diluted in $1.3 \%$ normal goat serum. Immunostaining was amplified using Vector Laboratories Elite ABC kit (Vector Labs) and the immunoperoxidase complex was visualized with Nova Red (Vector Labs). Counterstaining was performed with Mayer's haematoxylin (1:4). Expression of UCP1 was quantified using Image J software (version 1.47) and expressed per area and per total fat pad.

Atherosclerosis quantification. Hearts were collected and fixated in phosphatebuffered $4 \%$ formaldehyde, embedded in paraffin and cross-sectioned $(5 \mu \mathrm{m})$ perpendicular to the axis of the aorta throughout the aortic root area, starting from the appearance of open aortic valve leaflets. Per mouse, four sections with $50-\mu \mathrm{m}$ intervals were used for atherosclerosis measurements. Sections were stained with haematoxylin-phloxine-saffron for histological analysis. For Apoe and $L d l r^{-1-}$ mice, paraffin-embedded hearts were cross-sectioned $(10-\mu \mathrm{m})$ and stained with modified Van Gieson stain. Per mouse, three consecutive cross-sections per $100-\mu \mathrm{m}$ intervals were used for atherosclerosis measurements, starting at the appearance of open aortic valve leaflets. Lesions were categorized for lesion severity according to the guidelines of the American Heart Association adapted for mice ${ }^{45}$. Various types of lesions were discerned: mild lesions (types 1-3) and severe lesions (types 4-5). Lesion area was determined using Image J Software (version 1.47). Quantification of smooth muscle cell actin was performed using antibody M0851 (Dako, Carpinteria, CA) and DAKO envision anti-mouse (Vector Laboratories Inc., Burlingame, CA). Rat monoclonal anti-MAC-3 antibody (BD Pharmingen, San Diego, CA) and Vector Impress anti-rat (Vector Laboratories Inc.) were used to quantify macrophage area. Immunostainings were amplified using Vector Laboratories Elite ABC kit (Vector Laboratories Inc.) and the immunoperoxidase complex was visualized with Nova Red (Vector Laboratories Inc.). Sirius red (Chroma, Stuttgart, Germany) was used to stain for collagen. The stability index was calculated by dividing the collagen by the macrophage area.

Statistical analyses. Statistical analyses between genotypes were assessed using the unpaired two-tailed Student's $t$-test. Univariate regression analyses were performed to test for significant correlations between uptake of ${ }^{14} \mathrm{C}$ activity in the liver and ${ }^{3} \mathrm{H}$ activity in intBAT, and between atherosclerotic lesion area and plasma lipid exposures during the study. Multiple regression analysis was performed to predict the contribution of plasma TG and TC exposures during the study to the 
atherosclerotic lesion area. The SQRT of the lesion area was taken to linearize the relationship with the plasma lipid exposures. Data are presented as mean \pm s.e.m., unless indicated otherwise. Differences at a probability level $(P)$ of 0.05 were considered statistically significant. SPSS 20.0 for Windows (SPSS, Chicago, IL) was used for statistical analyses.

\section{References}

1. Jukema, J. W., Cannon, C. P., de Craen, A. J., Westendorp, R. G. \& Trompet, S. The controversies of statin therapy: weighing the evidence. J. Am. Coll. Cardiol. 60, 875-881 (2012).

2. Hany, T. F. et al. Brown adipose tissue: a factor to consider in symmetrical tracer uptake in the neck and upper chest region. Eur. J. Nucl. Med. Mol. Imaging 29, 1393-1398 (2002).

3. Nedergaard, J., Bengtsson, T. \& Cannon, B. Unexpected evidence for active brown adipose tissue in adult humans. Am. J. Physiol. Endocrinol. Metab. 293, E444-E452 (2007)

4. van Marken Lichtenbelt, W. D. et al. Cold-activated brown adipose tissue in healthy men. New Engl. J. Med. 360, 1500-1508 (2009).

5. Virtanen, K. A. et al. Functional brown adipose tissue in healthy adults. New Engl. J. Med. 360, 1518-1525 (2009).

6. Cypess, A. M. et al. Identification and importance of brown adipose tissue in adult humans. New Engl. J. Med. 360, 1509-1517 (2009).

7. Zingaretti, M. C. et al. The presence of UCP1 demonstrates that metabolically active adipose tissue in the neck of adult humans truly represents brown adipose tissue. FASEB J. 23, 3113-3120 (2009).

8. Wu, J., Cohen, P. \& Spiegelman, B. M. Adaptive thermogenesis in adipocytes: is beige the new brown? Genes Dev. 27, 234-250 (2013).

9. Bartelt, A. \& Heeren, J. Adipose tissue browning and metabolic health. Nat. Rev. Endocrinol. 10, 24-36 (2014).

10. Shabalina, I. G. et al. UCP1 in brite/beige adipose tissue mitochondria is functionally thermogenic. Cell Rep. 5, 1196-1203 (2013).

11. Cannon, B. \& Nedergaard, J. Brown adipose tissue: function and physiological significance. Physiol. Rev. 84, 277-359 (2004).

12. Yoshida, T., Sakane, N., Wakabayashi, Y., Umekawa, T. \& Kondo, M. Anti-obesity and anti-diabetic effects of CL 316,243, a highly specific beta 3-adrenoceptor agonist, in yellow KK mice. Life Sci. 54, 491-498 (1994).

13. Fedorenko, A., Lishko, P. V. \& Kirichok, Y. Mechanism of fatty-aciddependent UCP1 uncoupling in brown fat mitochondria. Cell 151, 400-413 (2012).

14. Bartelt, A., Merkel, M. \& Heeren, J. A new, powerful player in lipoprotein metabolism: brown adipose tissue. J. Mol. Med. (Berl) 90, 887-893 (2012).

15. Bartelt, A. et al. Brown adipose tissue activity controls triglyceride clearance. Nat. Med. 17, 200-205 (2011).

16. Khedoe, P. P. et al. Brown adipose tissue takes up plasma triglycerides mostly after lipolysis. J. Lipid Res. 56, 51-59 (2015).

17. Geerling, J. J. et al. Metformin lowers plasma triglycerides by promoting VLDL-triglyceride clearance by brown adipose tissue in mice. Diabetes $\mathbf{6 3}$, 880-891 (2014).

18. Bartelt, A. \& Heeren, J. The holy grail of metabolic disease: brown adipose tissue. Curr. Opin. Lipidol. 23, 190-195 (2012).

19. Harms, M. \& Seale, P. Brown and beige fat: development, function and therapeutic potential. Nat. Med. 19, 1252-1263 (2013).

20. Dong, M. et al. Cold exposure promotes atherosclerotic plaque growth and instability via UCP1-dependent lipolysis. Cell Metab. 18, 118-129 (2013).

21. Heeren, J., Beisiegel, U. \& Grewal, T. Apolipoprotein E recycling: implications for dyslipidemia and atherosclerosis. Arterioscler. Thromb. Vasc. Biol. 26, 442-448 (2006)

22. Plump, A. S. et al. Severe hypercholesterolemia and atherosclerosis in apolipoprotein E-deficient mice created by homologous recombination in ES cells. Cell 71, 343-353 (1992).

23. Zhang, S. H., Reddick, R. L., Piedrahita, J. A. \& Maeda, N. Spontaneous hypercholesterolemia and arterial lesions in mice lacking apolipoprotein $\mathrm{E}$. Science 258, 468-471 (1992)

24. Ishibashi, S. et al. Hypercholesterolemia in low density lipoprotein receptor knockout mice and its reversal by adenovirus-mediated gene delivery. J. Clin. Invest. 92, 883-893 (1993).

25. De Haan, W. et al. Torcetrapib does not reduce atherosclerosis beyond atorvastatin and induces more proinflammatory lesions than atorvastatin. Circulation 117, 2515-2522 (2008).

26. Bijland, S. et al. Fenofibrate increases very low density lipoprotein triglyceride production despite reducing plasma triglyceride levels in $\mathrm{APOE}^{\star} 3$ Leiden.CETP mice. J. Biol. Chem. 285, 25168-25175 (2010).

27. Kuhnast, S. et al. Niacin reduces atherosclerosis development in $\mathrm{APOE}^{\star} 3$ Leiden.CETP mice mainly by reducing nonHDL-cholesterol. PLoS ONE 8, e66467 (2013)

28. van Vlijmen, B. J. et al. Diet-induced hyperlipoproteinemia and atherosclerosis in apolipoprotein E3-Leiden transgenic mice. J. Clin. Invest. 93, 1403-1410 (1994).
29. Rensen, P. C. et al. Selective liver targeting of antivirals by recombinant chylomicrons--a new therapeutic approach to hepatitis B. Nat. Med. 1, 221-225 (1995).

30. Saito, M. et al. High incidence of metabolically active brown adipose tissue in healthy adult humans: effects of cold exposure and adiposity. Diabetes 58, 1526-1531 (2009).

31. Dulloo, A. G. \& Miller, D. S. Energy balance following sympathetic denervation of brown adipose tissue. Can. J. Physiol. Pharmacol. 62, 235-240 (1984).

32. Wang, Q. et al. Brown adipose tissue in humans is activated by elevated plasma catecholamines levels and is inversely related to central obesity. PLOS ONE 6, e21006 (2011).

33. Yoneshiro, T. et al. Recruited brown adipose tissue as an antiobesity agent in humans. J. Clin. Invest. 123, 3404-3408 (2013).

34. Rensen, P. C. et al. Particle size determines the specificity of apolipoprotein E-containing triglyceride-rich emulsions for the LDL receptor versus hepatic remnant receptor in vivo. J. Lipid Res. 38, 1070-1084 (1997).

35. van Dijk, M. C., Ziere, G. J. \& van Berkel, T. J. Characterization of the chylomicron-remnant-recognition sites on parenchymal and Kupffer cells of rat liver. Selective inhibition of parenchymal cell recognition by lactoferrin. Eur. J. Biochem. 205, 775-784 (1992).

36. Cypess, A. M. et al. Activation of human brown adipose tissue by a beta3adrenergic receptor agonist. Cell Metab. 21, 33-38 (2015).

37. Trayhurn, P., Thurlby, P. L. \& James, W. P. Thermogenic defect in pre-obese ob/ob mice. Nature 266, 60-62 (1977).

38. Rothwell, N. J. \& Stock, M. J. A role for brown adipose tissue in diet-induced thermogenesis. Nature 281, 31-35 (1979).

39. Vijgen, G. H. et al. Brown adipose tissue in morbidly obese subjects. PLoS ONE 6, e17247 (2011)

40. van der Lans, A. A. et al. Cold acclimation recruits human brown fat and increases nonshivering thermogenesis. J. Clin. Invest. 123, 3395-3403 (2013).

41. Bakker, L. E. et al. Brown adipose tissue volume in healthy lean south Asian adults compared with white Caucasians: a prospective, case-controlled observational study. Lancet Diabetes Endocrinol. 2, 210-217 (2014).

42. De Lorenzo, F., Mukherjee, M., Kadziola, Z., Sherwood, R. \& Kakkar, V. V. Central cooling effects in patients with hypercholesterolaemia. Clin. Sci. (Lond) 95, 213-217 (1998).

43. Peronnet, F. \& Massicotte, D. Table of nonprotein respiratory quotient: an update. Can. J. Sport Sci. 16, 23-29 (1991).

44. Jong, M. C. et al. Apolipoprotein C-III deficiency accelerates triglyceride hydrolysis by lipoprotein lipase in wild-type and apoE knockout mice. J. Lipid Res. 42, 1578-1585 (2001)

45. Wong, M. C. et al. Hepatocyte-specific IKKbeta expression aggravates atherosclerosis development in $\mathrm{APOE}^{\star} 3$-Leiden mice. Atherosclerosis 220 , 362-368 (2012).

\section{Acknowledgements}

This study was supported by 'the Netherlands CardioVascular Research Initiative: the Dutch Heart Foundation, Dutch Federation of University Medical Centers, the Netherlands Organisation for Health Research and Development, and the Royal Netherlands Academy of Sciences' for the GENIUS project 'Generating the best evidence-based pharmaceutical targets for atherosclerosis' (CVON2011) and for the ENERGISE project 'Targeting energy metabolism to combat cardiovascular disease' (CVON2014). M.R.B. is supported by a personal grant from the Board of Directors of LUMC, P.P.S.J.K. by a grant of the Lung Foundation Netherlands (grant 3.2.10.048) and P.C.N.R. is an Established Investigator of the Netherlands Heart Foundation (grant 2009T087). A.B. is supported by a Postdoctoral Fellowship Award from the European Atherosclerosis Society (EAS) and a Research Fellowship from the German Research Foundation (DFG BA 4925/1-1). J.H. is supported by a grant from the Fondation Leducq-Triglyceride Metabolism in Obesity and Cardiovascular Disease. P.L.S.M.G. is supported by the European Community FP7 Award PIOF-GA-2010-273994. J.D.E. is supported by NIH grant GM33063 and P01 HL107150. Furthermore, we thank Lianne C.J.A. van der WeePals, Trea Streefland, Lisanne Naaborgh, Bianca de Roo and Chris van der Bent (Division of Endocrinology, Department of Medicine, LUMC, Leiden, The Netherlands), as well as Sandra Ehret (Department of Biochemistry and Molecular Cell Biology, Hamburg, Germany) and Karen Bowden (Department of Medicine at UCSD, La Jolla, CA, USA) for their excellent technical assistance, and Dr Jan B. van Klinken (Department of Human Genetics, LUMC, Leiden, The Netherlands) for help with statistical analysis. We thank A.J. Whittle and A. Vidal-Puig for critical discussions.

\section{Author contributions}

J.F.P.B, A.B., J.H. and P.C.N.R. designed the experiments, with the help from M.R.B. and P.P.S.J.K. J.F.P.B., M.R.B., P.P.S.J.K., A.B., C.S., A.W., S.K., G.H., I.M.M., C. John, C. Jung, N.V., L.P.J.B., P.L.S.M.G. and L.S. performed experiments and analysed data. J.F.P.B., M.R.B., P.P.S.J.K., A.B., G.H., P.L.S.M.G., J.H. and P.C.N.R. interpreted data. J.D.E, P.S.H., L.M.H. and L.D. provided intellectual contributions throughout the project. J.F.P.B., M.R.B., P.P.S.J., A.B., J.H. and P.C.N.R. wrote the manuscript. All authors 
discussed the results and commented on the manuscript. J.H. and P.C.N.R. were responsible for the overall supervision of the study.

\section{Additional information}

Supplementary Information accompanies this paper at http://www.nature.com/ naturecommunications

Competing financial interests: The authors declare no competing financial interests.

Reprints and permission information is available online at http://npg.nature.com/ reprintsandpermissions/
How to cite this article: Berbée, J. F. P. et al. Brown fat activation reduces hypercholesterolaemia and protects from atherosclerosis development. Nat. Commun. 6:6356 doi: 10.1038/ncomms7356 (2015).

(c) (i) This work is licensed under a Creative Commons Attribution 4.0 International License. The images or other third party material in this article are included in the article's Creative Commons license, unless indicated otherwise in the credit line; if the material is not included under the Creative Commons license, users will need to obtain permission from the license holder to reproduce the material. To view a copy of this license, visit http://creativecommons.org/licenses/by/4.0/ 